\title{
Taking a leap of faith: Meaningful participation of people with experiences of homelessness in solutions to address homelessness
}

Trudy Norman

University of Victoria, Canada

\author{
Bernadette Pauly \\ University of Victoria, Canada
}

Hilary Marks

Camosun College, Victoria, Canada

Dakota Palazzo

\begin{abstract}
Participation of people with experiences of homelessness is critical to the development of meaningful strategies to end homelessness. The purpose of this study was to gain insights from people who have been homeless in a mid-sized Canadian city, as to strategies that facilitate meaningful participation in solutions to end homelessness. Within an overarching framework of collaborative research, we collected data through seven focus groups and employed interpretive description as our approach to data analysis. In our analysis, we identified both exclusionary and inclusionary forces that impact participation. Exclusionary forces included being 'caught in the homelessness industry', 'homelessness is a full time job' and facing stigma/discrimination that make participation a 'leap of faith'. Inclusionary forces included earning respect and building trust to address unequal power relations, and restoring often 'taken for granted' social relations. Specific strategies to enhance participation include listening, valuing skills and stories, and supporting advocacy efforts. The study findings illuminate ways in which power imbalances are lived out in the daily lives of people who experience homelessness, as well as mitigating forces that provide direction as to strategies for addressing power inequities that seek to make participation and social inclusion meaningful.
\end{abstract}

Keywords: homelessness, social policy, social exclusion, social inclusion, advocacy

Homelessness $^{1}$ as a social issue of concern did not exist in Canada before the 1980's (Hulchanski, 2009). Beginning in the 1970's, a series of neoliberal influenced changes in federal policy direction culminated in cessation of the federal housing program in 1995, with dramatic changes to key health and social programs along the way (Gaetz, Donaldson, Richter \& Gulliver, 2013; Hulchanski, 2005; Shapcott, 2009). In several provinces, these

\footnotetext{
1. Homelessness encompasses a range of physical living situations including: 1) Unsheltered, living on the streets or in places not intended for human habitation; 2) Emergency Sheltered, including those staying in overnight shelters for people who are homeless, as well as shelters for those impacted by family violence; 3) Provisionally Accommodated, referring to those whose accommodation is temporary or lacks security of tenure, and 4) At Risk of Homelessness, referring to people who are not homeless, but whose current economic and/or housing situation is precarious or does not meet public health and safety standards (Canadian Homelessness Research Network, 2012).
}

Correspondence: Trudy Norman (trudyn@uvic.ca)

changes have resulted in dramatically restricted entitlements and access to income assistance (Reitsma-Street \& Wallace, 2004) and employment insurance (Mirchandani \& 
Chan, 2007). Not surprisingly, the rate and overall numbers of people experiencing homelessness in Canada continues to be of concern (Gaetz et al., 2013). There have been calls across North America for a shift from managing homelessness through emergency responses to 'ending homelessness' (Gaetz et al., 2013). Across Canada many jurisdictions have developed plans to 'end homelessness' and advocated for the voices of homeless people to be included as part of strategies to end homelessness (Calgary Homeless Foundation, 2011; Edmonton Committee to End Homelessness, 2009; Greater Victoria Coalition to End Homelessness, 2012).

In the European context, the Federation of National Organizations Working with the Homeless (FEANTSA) (2009) has stressed the importance of including people with lived experience of homelessness in decisions that affect them. Much work has also been done in Australia on the social inclusion of people with experiences of homelessness (Arthurson \& Jacobs, 2003). 'Social inclusion' as a concept, however, is variously defined in the literature (Norman \& Pauly, 2013). Social inclusion can be understood as a social determinant of health. Social inclusion/exclusion as a process influences access to rights, capabilities and resources at individual, group, community and societal levels impacting the resources for health (Mikkonen \& Raphael, 2010, World Health Organization Europe, 2015). In such an approach, inclusion in social, political, cultural and economic decisions that affect you, are central to achieving social justice and equitable health outcomes.

Principles of social inclusion have emerged in discourses on disability and the mental health consumer movement (Hickey \& Kipping, 1998), HIVIAIDS (Unaids, 1999), illicit drug use (Jurgens, 2005) and homelessness (Barrow, McMullin, Tripp \& Tsemberis, 2000; Paasche, 2009; Owen, 2009; Whiteford, 2011). Recently, the Mental Health Commission of Canada included an explicit goal to engage and bring forth the voices of people experiencing mental illness and homelessness in the At Home/Chez Soi Study (Goering et al., 2012). People with experiences of homelessness provided important understandings to At Home/Chez Soi researchers, such as knowledge of available supports for participants in study communities and, in the case of the Toronto consumer Caucus, people with lived experience were "inhouse experts', grounding the project in the consumer perspective" (Nelson et al., 2014). Many insights were gained into how to include people with lived experience in future research (vanDraanen et al., 2013). Further, Norman \& Pauly note "Without the voices of those impacted by homelessness, there is a risk that important understandings essential to the development of effective solutions to homelessness will remain obscured" (2013, p. 136). However, there is little evidence of practical strategies that promote inclusion of people with experiences of homelessness in policy development and solutions to ending homelessness from the perspectives of those experiencing homelessness (Norman \& Pauly, 2013).

Social inclusion ${ }^{2}$ of persons experiencing homelessness in policies and strategies to end homelessness and the need for evidence based strategies were identified as a priority by the Greater Victoria Coalition to End Homelessness (GVCEH). GVCEH is a partnership of nonprofit health and social service organizations, the business and faith communities, and government with a goal to end homelessness by 2018. Specific recommendations to foster meaningful participation and social inclusion, along with several attempts at developing an experiential working group, are highlighted in GVCEH documents (Pauly, Jackson, Thompson \& Kerr-Southin, 2011). In the first phase of this project, we undertook a scoping review of the literature on social inclusion and homelessness (Norman \& Pauly, 2013). In this, the second phase of the project we sought to engage people with experience of

2. 'Social inclusion' is defined here as meaningful participation of people with experience of homelessness in decisions that affect them (Norman \& Pauly, 2013).

homelessness to gain an understanding of strategies that would foster participation in solutions to end homelessness as part of a community coalition. In this paper, we review 
social exclusion and barriers to participation for those who are homeless, provide an overview of the project and describe the perspectives of people experiencing homelessness on social inclusion in solutions to end homelessness. We present recommendations that may serve as signposts or beginning steps for future initiatives that seek meaningful participation of people with experiences of homelessness in developing solutions to end homelessness.

\section{Purpose and aim}

The aim of this project was to obtain the views and opinions of people with experience of homelessness on strategies that could foster meaningful participation in developing solutions to homelessness. In particular, we sought to inform the development and implementation of a policy and related strategies for enhancing social inclusion of people with experiences of homelessness in the work of the GVCEH and community coalitions aimed at ending homelessness.

\section{Background}

People who experience homelessness frequently experience social exclusion and face barriers to meaningful participation in policy processes and developing solutions to homelessness (Norman \& Pauly, 2013). Fundamentally, structural conditions and processes rooted in unequal power relations work to "exclude people from housing, income supports and respect that are needed for participation as social and political equals" (Norman \& Pauly, 2013, p. 139). Galabuzi argues that social exclusion is "an expression of unequal power relations among groups in society which then determine unequal access to economic, social, political, and cultural resources" (2009, p. 254). By this definition, people who are homeless are socially excluded, as they lack adequate income to afford the necessities of life and must spend the vast majority of daily life meeting survival needs. They may have little time or energy participate in other activities. Conversely, social inclusion refers to "economic inclusion, adequate income, housing, and access to health care and supports, along with the ability to participate in social and cultural activities" (Norman \& Pauly, 2013, p.140).

Unequal power relations, power exercised through social relations, impacts the actions of others and "where there are power imbalances, this exercise of power can control, oppress or constrain others" (Belle-Isle, Benoit \& Pauly., 2014, p. 181). Participation may actually be a marginalizing experience in which their views and perspectives are not seen as credible, or they are met with stigma, stereotypes and myths about homelessness (Whiteford, 2011). Thus, there are considerable power inequities that act as barriers to participation of people with experience of homelessness in strategies to end homelessness (Norman \& Pauly, 2013; vanDraanen et al., 2013).

Key among these barriers for people who are homeless is a 'devalued identity' associated with experiences of 'poverty stigma' (Reutter, Stewart, Veenstra, Love, Raphael \& Makwarimba, 2009). Poverty stigma is often experienced alongside other forms of stigma such as that associated with mental illness, illicit drug use, single parenthood (primarily mothers) and racial or ethnic status (Reutter et al., 2009). For example, people who experience homelessness may be constructed as lesser or 'second class' citizens through understandings of people in poverty as indolent, uncontrolled and worthless, due to perceived lack of paying employment, non-conforming speech or dress, and soliciting donations or 'begging' on city streets. They may be 'spatially marginalized' (Laurenson \& Collins, 2006) or seen as "inferior, dirty, and disruptive non-persons" (Hodgetts et al., 2008, p. 939). People who experience homelessness may be subject to increased surveillance by police as a result of social profiling (O'Grady, Gaetz \& Buccieri., 2011) and associations between homelessness and perceived criminality (Sheehy, 2004). Poverty stigma frequently 
overlaps with 'drug related stigma', particularly illicit drug use that tends to associate and marginalize those who are poor as being unclean, criminals and dangerous (Lloyd, 2010, Room, 2005). In addition, lack of attention to ethnicity and gender (Kingfisher, 2005), mean that important nuances of the experiences of people who have been homeless are lost in the development of appropriate solutions to homelessness. Thus, participation and social inclusion are often restricted as a consequence of these stereotypes. In our work, we were particularly interested in how to overcome barriers to social inclusion through attention to systemic policies and processes in community level solutions to ending homelessness.

\section{Method}

We drew on an overarching framework of collaborative research. This corresponds to Mcdonald's (2012) call to privilege the views of participants and encourage participation in the research process of peer researchers, those affected by homelessness, to achieve a goal of contributing to a specific social change. The ideas for this research were initiated by the GVCEH. Both the GVCEH and people with experiences of homelessness informed the process of data collection and analysis. We collected data through focus groups to explore the perspectives of people experiencing homelessness in a variety of settings (see Ruff, Alexander \& Mckie, 2005, Sakamoto et al., 2008 for information on focus groups). Focus groups can help to elicit the perceptions, beliefs, or opinions of a group of people (generally 6-12) on a specific area of interest. Rich and varied data can emerge from focus groups. Spirited interaction amongst participants can encourage related memories or fresh thinking opening a space for new insights to emerge.

A critical aspect of conducting the research was the engagement, training and participation of a peer researcher. A person with experience of homelessness brings knowledge, skills and perspectives not otherwise available to the project (Sakamoto et al., 2008), increasing the potential for new research insights. Following Guta, Flicker and Roche (2010) a job description outlining the skills, abilities and experience expected of a peer researcher was drafted and circulated to numerous social agencies serving people with experiences of homelessness. Upon hiring, the peer researcher received training in data collection, analysis and ethical considerations.

The peer researcher was a full member of the research team, assisting with recruitment of participants, facilitating focus groups, collection and analysis of data and reviewing manuscript drafts. The peer researcher was well known in the local context and may have also provided a sense of safety and familiarity to participants. She contributed understandings of the lived experience of homelessness not available to academic researchers (Sakamoto et al., 2008). These understandings significantly assisted in data analysis and interpretation of findings. Again, following Guta and colleagues (2010), significant attention was paid to support and supervise the peer researcher. Developing open dialogue with academic researchers through relationship building and providing opportunities for debriefing were key in addressing potential unequal power relations between the peer and academic researchers. The peer worked closely with the first author receiving training and individual support to enhance her skills throughout the project. In addition to the two academic researchers and peer researcher, we engaged a community based researcher with knowledge and experience working in the field of homelessness. The GVCEH was developing a Social Inclusion Advisory Group (SIAC) ${ }^{3}$ at the time of this project. Members of that group assisted in reviewing and interpreting findings.

3. SIAC is a group of $15-20$ people with experiences of homelessness that regularly provide input to the GVCEH on a range of initiatives.

\section{Data collection}

Recruitment of focus group participants took place through invitations posted at social service agencies frequented by people who experience homelessness. Multiple focus group 
locations were selected to increase the potential for engagement with various subgroups of people experiencing homelessness: youth, men, women, and families, including a specific focus on agencies that service Aboriginal people.

Participants were paid a stipend of fifteen dollars and provided with bus tickets to acknowledge their participation in the research. Snacks were provided during the focus groups and childcare arranged. The focus groups lasted from one to two hours. Each focus group was digitally voice recorded and hand written notes made on a flip chart for participants to peruse and add to if they wished.

Ethical approval for the research was obtained from the sponsoring university. At the beginning of each focus group, the study was explained and participants provided with a copy of the interview questions and the demographic form. Opportunities to ask questions about the research occurred at the beginning and throughout the focus group. At least two, and often three researchers, were present during each focus group. Each group was facilitated by the graduate student and peer researcher with the academic and community based researcher providing additional support, feedback and observation. This proved to be a helpful team approach as in at least one example, a participant became visibly upset during the process and the academic researcher was able to debrief an individual questioning the validity or usefulness of the focus group when it appeared that there was no motivation or will on the part of those with power to make changes.

\section{Sample}

Sixty-three people took part in seven focus groups, with two to fifteen people in each group. Participants identified as male (49\%), female (49\%) and one person identified as transgendered. Participants identified as Caucasian (59\%) and Aboriginal, First Nations or Métis (41\%). The age or participants ranged from 20 to 60 years of age with the majority between 41 and 60 years (62\%). There were eight youth participants (13\%) aged 20 to 30 years. The majority of participants were single (64\%). Sixty-two of sixty-three participants reported at least one source of income with almost half (48\%) reporting provincial income assistance as their primary revenue source. Twenty-two percent (22\%) of participants indicated that they took casual work to supplement income assistance and $25 \%$ indicated they did alternative work such as panhandling, binning and recycling. Over half $(55 \%)$ of participants lived in the region for more than ten years with $25 \%$ living in the area between four and ten years.

Over two-thirds of participants (68\%) could be considered homeless at the time of the research. Eleven people were unsheltered, 15 were emergency sheltered and 19 were provisionally accommodated in a rooming house or hotel. Fifteen people were housed (living in an apartment) with past experiences of homelessness. The housing status of the three remaining participants was unknown.

Homelessness was a recurring experience for 18 (29\%) of participants. Of the 28 participants reporting the number of times homeless, the median was four, with a range of one to 140 times. Seventeen people (27\%) were without permanent housing "too many [times] to count" or "constantly" over a period of at least ten years. Twenty (20) participants reported from one to nine moves in the past year (32\%) with a median of two moves. Twenty-eight participants (44\%) stayed in a shelter in the past year with seven spending staying more than thirty days. Despite such precarious circumstances people willingly shared their views on the challenges of meaningful participation in 'ending homelessness' while homeless, insecurely housed and living in poverty.

\section{Data analysis}


We employed interpretive description as our approach to data analysis, in line with Thorne, Kirkham and Macdonald-Eames (2008). Interpretive description fosters a level of abstraction through the process of analysis to develop broader notional understandings and adequate detail to develop insights to inform practice (Thorne et al., 1997). "Interpretive description in nursing requires that nurse researchers come to know individual cases intimately, abstract relevant common themes from within these individual cases, and produce a species of knowledge that will itself be applied back to individual cases (Thorne et al., 1997, p. 175). The academic researcher is a nurse, and both she and the graduate student researcher situate their work within social determinants of health perspective making this frame appropriate for analysis.

All sessions were audio recorded and transcribed. Transcripts were read repeatedly and coded inductively for both socially inclusive and exclusionary practices by all members of the research team. All four researchers met throughout the process to compare codes and develop a shared coding framework. The team generated an initial list of themes, which were refined and collated with supplemental information from the notes to inform the analysis. The team met several more times to further analyze the data, develop the themes and finalize interpretations. Initial findings were shared with a group of people who had experienced homelessness to assist with interpretation and provide an 'outsider' view. All but one participant in this group were not involved in the initial data gathering process. The findings resonated with the members of this group. For example, this broader group strongly agreed with the notion of homelessness as full time work. As one woman said, "The whole day you go from point $A$ to $B$ trying to survive...from the moment you open your eyes in the morning until you close your eyes you're in survival mode".

\section{Results}

Our findings indicate that a number of barriers exist in the daily lives of people who experience homelessness that severely hamper their ability to meaningfully participate in decisions that affect them, including the development of solutions to end homelessness. For many individuals, participating in solutions and strategies to end homelessness at a systemic level (e.g. funding and policies) was less pressing than a need to address exclusion from decisions that affected them at the programmatic or service agency level. However, participants identified a number of factors that, if present, would facilitate their ability to participate in all aspects of addressing homelessness in the community. These influences fell into two main categories we termed 'exclusionary forces' and 'inclusionary forces'. We describe each broad category below and several sub-categories within each category to provide insight into strategies that can remove barriers and facilitate meaningful participation of people with experience of homelessness in solutions to end homelessness.

\section{Exclusionary forces}

Forces that work to exclude individuals from meaningful participation include being 'caught in the homelessness industry', 'homelessness is a full time job' and the manifestation of stigma and discrimination as a lack of respect for people who experience homelessness when accessing services. Together, these factors lead to an overall feeling of powerlessness among people who experience homelessness, and feelings of limited ability to influence decision-making and actions to end homelessness. The overwhelming result was most people had little faith that their participation in the 'system' of social services or government at any level, would help to address homelessness. So, participation requires a 'leap of faith'. Examination of exclusionary forces highlights the challenges individuals face when attempting to have their voices heard in the midst of day-to-day survival and contains important learnings that can be used to foster opportunities for true and meaningful participation. 
Caught in the homelessness industry

Participants expressed their belief that homelessness is institutionalized and that social agencies are invested in the continued existence of homelessness because their livelihoods depend on it. One male participant commented, "Their (agency) mandate is self-preservation ...they're here only for the pay cheque and that's it". This comment, in different forms, was made in every group; a referent to what some participants termed 'poverty pimping', a phrase that highlights the anger and resentment many felt toward the large number of social agencies that people who are homeless depend on for shelter, food and support. Participants emphasized the lack of incentives to end homelessness among those who provide homelessness services and widely perceived absences of care for people who homeless agencies are mandated to serve. We term this plethora of agencies, lack of incentive and perceived attitudes together as the 'homelessness industry'. Participants perceived that even if they give voice to concerns and ideas "no one is listening so why participate" and give energy to a system that is seemingly uninterested and unmovable. A youth observed, "Who are we supposed to talk to that's going to actually listen?"

Homelessness is a full time job

Frustration and exhaustion characterized the comments of participants who spoke of spending many hours walking from one service to the next throughout the city. Most often 'foot power' is the only form of transportation available to people who are homeless. When an individual arrives at a destination (s)he may find long lines and a significant wait for service. This 'line-up and wait' scenario may be repeated several times in one day. As a youth told us:

It's annoying when you're trying to access services, 'cause you have to have an appointment here... and then go across town, have an appointment there...then you got to have all your paperwork with the right things dotted...then they got to do a back check. It takes me all day...or days, and everywhere I go, everybody I talk to I have to tell the story again.

Coordinating meal services, along with registering for a shelter bed and attending health or income assistance appointments, can take all the energy an individual has in a day, with little energy left to participate in other activities. Homelessness is, as one male participant noted, "a full time job... just getting my basic needs met". Most opportunities to participate in planning or feedback sessions are scheduled between 9am and 5pm; regular working hours for many agency staff. Participating in one of these sessions, should an individual wish to do so, may require that person to miss an opportunity for a meal as no-cost meal sittings are often held between $11 \mathrm{am}$ and noon and $4 \mathrm{pm}$ to $5 \mathrm{pm}$ and may necessitate lining up at least thirty minutes prior to the scheduled meal time in order to ensure an individual can eat. Obtaining a shelter bed for the night often requires 'signing in' for a bed at 3pm, or if an individual is looking for shelter for the night, waiting in line to see if a bed becomes available. Should an individual not be present if his or her name is called from the waiting list (s)he will not obtain a bed for the night. Other living requirements must fit around this schedule for eating and sleeping. Individuals must attend appointments with income assistance workers to obtain or stay in receipt of funds and appointments generally take place only during weekday hours. Attending appointments may require a significant walk to the income assistance office or a wait as workers often carry enormous caseloads.

Missing scheduled meal or bed registration times at a shelter or a meeting with an income assistance worker to take part in a feedback session may have a serious impact on whether an individual has enough to eat or a roof over her head that night. As one man noted, "Every hour of the day is dedicated to survival". The "work day' of someone who is homeless highlights the challenge of meeting survival needs and the lack of time and energy available 
to participate in other activities. Further, participants observed that though they perceived numerous injustices were experienced by fellow service users, the arduous work of getting life needs met means 'nothing is left in the tank' for helping others. As one man said 'You spend all of your energy just trying to put food in your belly. By the end of the day, the last thing you want to do is...stand up for 500 people and fight that fight, too". The provision of food, stipends, transportation and childcare are unquestionable and essential resources to not only support participation but to ensure survival (Norman \& Pauly, 2013).

\section{Facing stigma and discrimination}

Participants often described lack of respect in interactions with homeless services. As a female youth said, "And it'd be really nice if when we go to ask for help, that we weren't treated like we're worthless. I want to still have all my choices and be treated like a real person." Coping with stigma and discrimination as individuals go about their day in the community can make the work of being homeless more difficult and act as a barrier to participation. One male participant noted the difficulty in qualifying for tenancy once he found a residence, "They won't answer your calls if you're on welfare. As soon as they hear... 'intent to rent'... or even if you're on El (employment insurance)...they don't (want you)".

In addition to poverty stigma, racism was a common experience. As one Aboriginal man observed, "anyone who is homeless is presented with a 'get out of Dodge' mentality", a "we don't want you here, keep away" message. A female participant reported no longer attending one overnight shelter as she felt discriminated against because of her Aboriginal status, a sentiment reiterated by other participants who felt racism played a clear role in their challenges in accessing shelter and supports. Another Aboriginal woman spoke of her encounters with police, "I suppose if I had blonde hair, blue eyes, and I was a white woman, then you would jump at it (take her concern seriously) or why another young woman was homeless "speaking on Aboriginal terms...there's a big stigma, 'Oh, you guys have free land. Why don't you just go live there?"'

\section{Participation means taking a leap of faith}

As described above, participants expressed a sense of powerlessness and lack of faith that the system would ever change. One female youth commented, "What we meet on a daily basis are people that are just the billboards for the organizations. They have no staying power. They have no change-making ability. If I complain to them it's not going to go anywhere because they're not a change-maker". In the face of myriad daily challenges, some participants still attempted to have their voices heard and shared, to let people know that even when one voices their ideas, nothing seems to change. A female participant suggested that should an individual provide feedback despite the challenges, nothing may come of it, "are there actually going to be things that happen with what I say, and with what I share? I've shared my story numerous times now... and it doesn't seem to make a difference at all." One man stated "I feel like I've made some decent suggestions. I'm out of work right now and it's strange being on this side... and I'm wondering how much I'm being heard now that I'm one of the voiceless in the community". Indeed, it seems there are times when people are effectively silenced when they attempt to give feedback. Another participant voiced his many attempts to give feedback this way "When a staff member laughingly says, 'you know where they go'. I go, 'no'. 'Like, file nine'. File nine. Garbage. They don't even read it. Shredder. Sometimes they read them, but there doesn't seem to be any positive action". The experience of participants is that their feedback is ignored or dismissed and they have little evidence of any changes.

Again, participation requires a 'leap of faith' in the face of a continuous struggle to get life needs met and an overwhelming sense that ;no one is listening; when individuals try to voice concerns or provide feedback. Taking such a 'leap of faith' is a risk, in that an individual may 
have to leave basic needs unmet and may be ignored, reproved, or even censured in efforts to participate. In a real sense 'participation' can put an individual's survival at risk. For example, the choice to delay eating, buy food, or miss a meal is taken for granted by those who do not have to make such choices. Participation in the face of almost certain cost to wellbeing then becomes both a leap of faith and an act of courage. Participants valued involvement and many wanted to contribute despite the risks to do so. Participants shared their thoughts with us and spoke clearly on what they saw as necessary circumstances for meaningful participation. We termed these pre-conditions 'inclusionary forces'.

\section{Inclusionary forces}

Inclusionary forces work to assist people with experience of homelessness in providing feedback to service providers, foster positive relationships with those who are providing services and promote opportunities to meaningfully engage in developing solutions to homelessness. These influences also work to mitigate the risks of participation by actively addressing unequal power relations between service providers and users by restoring aspects of relating that are often 'taken for granted' in everyday life.

\section{Earning respect}

Strategies aimed at promoting meaningful participation begin with earning respect of people with experiences of homelessness. Lack of respect is a common experience and not knowing if you will be respected dictates that respect must be demonstrated by others first. This is particularly relevant in service agencies as agency staffs have greater power by virtue of their ability to deny services. This power imbalance must be acknowledged and addressed. As one participant observed, "I think that's part of homelessness. You start hating yourself, right? You start getting down on yourself, and then you still have to deal with all these agencies [who think] that you're just one of 'those kind' of people. You're not getting respect".

Respect may be demonstrated in many ways. Openness to interaction and a willingness to listen were very important acts of respect for participants. One man told us he would have felt respected "If one of the staff members actually brought you in and said...okay, we looked at your suggestion... Here's what we think". Discussing the rationale behind a policy was another example of respect necessary for participation. For example "[We] would feel a lot more part of the process if we were just told why things were set up the way they were". One male participant added, "Stuff like the rules. There's a lot of them, and you have to follow them... but there's a lack of discussion behind why they're there, and I find that that can often be a dehumanising sort of aspect to it... it does make us feel like children or cattle".

Engaging people in dignified and respectful ways demonstrates to people experiencing homelessness that they deserve fair treatment and helps counter power imbalances.

\section{Building trust}

Fostering inclusion through developing trusting relationships requires seeing people as unique individuals first and people who are homeless and needing service second. As one man offered, "We all came from different places, and we all have different experiences". There is also much diversity among people who experience homelessness, as one male participant advised, "Don't group everybody together, "cause we're not all the same".

Participants offered a number of suggestions they perceived would help to build the trust that is foundational to participation. Feeling understood by agency staff was seen as vital to feeling like they can participate "Like, I [staff] have empathy for your pain. And I'm willing to be there, listen, not just say, 'Yeah, yeah I hear you'". Several participants suggested that agencies should hire people who have been homeless to ensure staff had empathy for their experiences, "We want people that know us well around us, that we're comfortable with... and well connected with, and can support us, and we can support each other". Following 
through on complaints and addressing concerns also work toward building trust with service users, as one man said "the comment box....but what happens with these suggestions and comments after they're put in the box, who knows?" Such actions foster mutual respect and support conditions in which trust can flourish.

\section{Strategies for meaningful participation}

Our findings indicate that people with experiences of homelessness feel their input is rarely valued and often dismissed. Contributing at a service level was key strategy suggested by many participants as they must access services to meet their basic life needs. Participants wanted to see their time and effort influence positive changes in their daily lives and contribute to positive changes in service agencies for everyone. As one participant proposed, "Make it feel like you being there is going to make a difference in your life". Several participants suggested regular agency 'house' meetings to share ideas or concerns "A committee, or a group, make it a standing thing that happens every month". Others thought a Community Liaison or Ombudsperson to represent service users might work better because as one man noted, "Most of us wouldn't be able to...remain calm for long enough to get our point across. It's the frustration factor, when you've dealt with it...for months and months and months." This suggestion was echoed by participants in several groups.

Participants were also interested in taking part in efforts to address homelessness at the systems level. Meeting with 'change makers' to help them understand homelessness, telling their stories on a website, public speaking, rallies and collective action, and peer support through self-organising such as a tenants' union or advocacy groups were suggested as potentially useful in gathering people together to influence systemic change. Preventing homelessness was also on participants' minds. Several participants thought school presentations may be useful as both a way to help youth understand homelessness and warn them away from the street "The only way that they're going to know is by somebody who's been there, somebody who has experienced homelessness". These suggestions highlight the importance of valuing experiences of homelessness and creating opportunities in which these experiences are respected, listened to and valued as part of solutions.

\section{Discussion}

People who experience homelessness often have limited time and resources to participate in policy and programs to end homelessness, as they must meet subsistence needs such as finding a place to sleep and adequate food to eat. They often lack opportunities to participate in policies and programs in ways that are meaningful to them. Our findings also indicate that people with experience of homelessness wish to participate in developing solutions and strategies to end homelessness on both programmatic and systemic levels Further, participants offered a range of strategies and tactics that would facilitate their participation in efforts to address homelessness.

Lack of resources to participate (e.g. housing, income, transportation), the gendered nature of power, historical attitudes to Aboriginal peoples that have fostered ongoing systematic racism in Canada (Kingfisher, 2005; 2007) coupled with multiple and intersecting stigmas associated with homelessness (Pauly, 2014) must be acknowledged as the daily environment in which attempts to build trusting relationships and foster meaningful participation of people who experience homelessness take place. Participant experiences of poverty stigma (Reutter et al., 2009) and racism as forms of stigma and discrimination that operate in systems (Browne et al., 2012; Kingfisher, 2005) add to feelings of being 'unwelcome' and contributing to an overwhelming feeling that they and their input are neither valued nor appreciated. Not surprisingly, participants felt a lack of trust that their feedback would be heard and that offers of participation were genuine. Such feelings of distrust are 
borne of life experiences and therefore, trust must be earned (Pauly, 2014). Mutual respect is the foundation for building trust and developing relationships with people who have experienced homelessness (Pauly, 2008). Trust has been found to be the currency of relationships with people who experience homelessness and are seeking health care (Pauly, 2008; 2014).

The material deprivation associated with homelessness coupled with multiple and intersecting stigmas that people who are homeless often experience constitute a 'double whammy' that contributes to marginalization and systematic exclusion from meaningful participation in decision-making processes from service agencies to larger systemic levels.

First, addressing material needs such as the provision of food, stipends, bus tickets and childcare are thus minimal requirements for meaningful participation of people who experience homelessness in decisions affecting them (Norman \& Pauly, 2013). The participants in our study told us that they want to provide feedback to social agencies and make services better for themselves and others, a direct response to negative and discriminatory experiences at these agencies. Providing feedback is clearly a primary need for participants as they must receive service from social agencies to survive.

Second, participants want to contribute to developing solutions to homelessness that foster real structural change, hence the numerous suggestions for advocacy activities. However, study participants noted they often have little willingness to contribute when participation may increase the risks of homelessness, in that their survival needs may not be met for that day (Williams, 2005). Indeed, giving feedback is particularly difficult for people who experience homelessness, as they often experience a lack of dignity and respect, racism and discrimination in daily life, and are particularly at risk when offering feedback to social agencies that provide basic material needs to sustain life. It may be less risky to say nothing at all. Meaningful participation may become less risky when it does not mean the possibility of foregoing a meal, a bed for the night, physical and emotional exhaustion or enduring dismissive or disrespectful treatment at a service on which one's existence depends. Dignity, respect, open communication and development of trusting relationships are the necessary conditions for participation along with a base of adequate material supports (Norman \& Pauly, 2013).

People who experience homelessness are uniquely qualified to contribute to improving service provision and developing solutions to homelessness (Sakamoto et al., 2008). Strategies to address homelessness on a systemic level offered by participants can promote meaningful participation as well as advocate for structural change. For example, telling stories on a website provides space for individual voices and legitimizes experience. Public speaking and meeting with 'change makers' promote people with experience of homelessness as creditable sources of information on homelessness as well as social agency representatives and members of the academy, while organizing and collective action can foster group identity and support political action taken by other groups in society. In each case people with experience of homelessness take a position that their voices be heard and their needs addressed, thereby challenging prevailing power relations that work to further marginalize and exclude them from participation in decisions that affect them.

For people who are homeless the 'included' often means social agency personnel, boards of directors and ultimately government departments that fund housing, income assistance and social support programs essential to people who are homeless. Walsh, speaking from a human rights perspective, states that "a political decision must be made that the inclusion of socially excluded groups such as the homeless is a 'good' worth paying for" (2006, p. 200). Until such programs are universally available and adequately funded, people who are homeless "are not likely to realize their 'right' to inclusion" (Walsh, 2006, p. 200). 
If 'social inclusion' means integration into a neoliberalized social structure then its usefulness may be questionable (Porter \& Craig, 2004). It is then important that organizations of people with experience of homelessness (Anker, 2008) be supported to foster meaningful participation in a range of decisions that affect them. Such organizations can provide skill development and a range of learning opportunities that enhance the daily lives of people who are homeless and a venue for input to social agencies and governments (Anker, 2009).

\section{Limitations}

There are several limitations to this work. The study took place in a mid- sized urban Canadian city so may not reflect the needs of people in rural or remote settings. Although attempts were made to engage a diverse group of homeless people, there are groups of people who experience homelessness including newcomers to Canada not represented here. Several participants noted that they had been "surveyed" numerous times over many years. However, despite these limitations, this study provides some important insights to help people who have experienced homelessness to contribute to the development of policy and practice enhancements.

\section{Conclusion}

People who experience homelessness often have few opportunities to meaningfully participate in decisions affecting them. Surfacing and addressing unequal power relations is critical to meaningful participation and real inclusion of people who experience homelessness in a range of decisions that affect them (Norman \& Pauly, 2013). The current study illuminates some ways in which these power imbalances are lived out in the daily lives of people who experience homelessness providing direction and ultimately, fostering strategies that may begin to address those inequities in the real world setting of the GVCEH and its partner organizations.

Participants clearly told us they wish to take part in developing strategies and solutions to end homelessness, yet doing so may threaten their survival and well-being. This is not a choice anyone should have to make. Responsibility for fostering inclusion rests with those who are already included (Kennedy \& Fitzpatrick, 2001). In light of the findings and the overall aim of this project, recommendations for enhancing inclusion of people with experience of homelessness in solutions to ending homelessness focused on creating common ground for participation to support participants to 'take a leap of faith'. 'Common ground' is physical and relational. Physical aspects include a comfortable meeting space and adequate washroom facilities. The material needs of people who experience homelessness must also be addressed including the provision of food, childcare, transportation and stipends to acknowledge the value of their contributions. Relational needs refer to the creation of trust. This includes demonstrated values of dignity, respect and as one participant noted "ethos, pathos, and logos"; in this context an ethical stance in which all are held accountable for the work, acceptance of the feelings of all participants and provision of timely, accurate information in ways that everyone can understand so the work may progress in a timely manner. It is of note that the GVCEH has incorporated strategies outlined in this work to further development of its Social Inclusion Advisory Committee (SIAC) to inform GVCEH work. Finally, we recommended institutionalized support for peer run organizations of people with experience of homelessness to provide opportunities for development of a concerted voice, strategic direction, service recommendations and advocacy on behalf of their members without the constraints often imposed by larger funding agencies. This has been done in various forms in the United States (Williams, 2005), Canada (Greene, 2005) and Denmark (Anker, 2008). 
Understanding social exclusion and inclusion from the perspective of a range of groups who experience homelessness requires further examination. It is in working in partnership with people who experience homelessness as colleagues that we will begin to understand viscerally what social exclusion means, how participation may be facilitated and indeed, inclusion fostered in ways people who experience homelessness find meaningful.

\section{Acknowledgements}

This research was funded by a grant from Mitacs Canada and VanCity Credit Union Community Investment Program. 


\section{References}

Anker, J. (2008). Organizing homeless people: Exploring the emergence of a user organization in Denmark. Critical Social Policy, 28, 27-50.

Anker, J. (2009). Speaking up for the homeless: Opportunities, strengths and dilemmas of a user organization. The European Journal of Homelessness, 3, 275-288.

Arthurson, K. Jacobs, K. (2003). Social Exclusion and Housing. Australia: Australian Housing and Urban Research Institute, Southern Research Centre.

Barrow, S., McMullin, L., Tripp, J. \& Tsemberis, S. (2007). Consumer integration and selfdetermination in homelessness research, policy, planning and services. Toward understanding homelessness: The 2007 National Symposium on Homelessness, National Alliance to End Homelessness.

Belle-Isle, L., Benoit, C. \& Pauly, B. (2014). Addressing health inequities through social inclusion: The role of community organizations. Action research, 12, 177-193.

Browne, A., Varcoe, C., Wong, S., Syme, V., Lavoie, J., Littlejohn, D., Tu, D., Godwin, O., Krause, M., Koushanbhi, J. K., Fridkin, A., Rodney, P., O'Neil, J. \& Lennox, S. (2012). Closing the health equity gap: evidence-based strategies for primary health care organizations. International Journal for Equity in Health, 11, 59-74.

Calgary Homeless Foundation (2011). Calgary's 10 Year Plan to End Homelessness: January 2011 Update. Calgary Homeless Foundation.

Canadian Homelessness Research Network (2012). The Canadian Definition of Homelessness. Toronto, ON: Canadian Homelessness Research Network.

Edmonton Committee to End Homelessness (2009). A Place to Call Home: Edmonton's 10 Year Plan to End Homelessness. Edmonton, AB: Edmonton Committee to End Homelessness.

FEANSTA (2009). Participation of people experiencing homelessness: Sharing the power and working together. Brussels, Belgium: FEANSTA.

Gaetz, S., Donaldson, J., Richter, T. \& Gulliver, T. (2013). The State of Homelessness in Canada 2013. Toronto, Canada: Canadian Homelessness Research Network Press.

Galabuzi, G. E. (2009). Social Exclusion. In: RAPHAEL, D. (ed.) Social Determinants of Health. Toronto, ON: Canadian Scholar's Press Inc.

Goering, P., Veldhuizen, S., Watson, A., Adair, C., Kopp, B., Latimer, E. \& Ly, A. (2012). At Home Chez Soi Interim Report. Ottawa, Canada: Mental Health Commission of Canada.

Greater Victoria Coalition to End Homelessness (2012). Solving Homelessness in British Columbia's Capital Region: A Community Plan. Victoria, BC: Greater Victoria Coalition to End Homelessness.

Greene, J.( 2005). "Whatever it takes": Poor people's organizing, OCAP, and social struggle. Studies in Political Economy, 75, 5-28.

Guta, A., Flicker, S. \& Roche, B. (2010). Peer Research in Action II: Management, Support and Supervision. Toronto, Canada: The Wellesley Instittute.

Hickey, G. \& Kipping, C. (1998). Exploring the concept of user involvement in mental health through a participation continuum. Journal of clinical nursing, 7, 83-88.

Hodgetts, D., Stotle, O., Chamberlain, K., Radley, A., Nikora, L., Nabalarua E. \& Groot, S. (2008). A trip to the library: Homelessness and social inclusion. Social \& Cultural Geography, 9, 933-953.

Hulchanski, D. (2009). Homelessness in Canada: Past, present and future. Calgary, AB: Growing Home, Housing and Homelessness in Canada.

Hulchanski, D. (2005). Rethinking Canada's Housing Affordability Challenge. Toronto, ON: Center for Urban and Community Studies, University of Toronto.

Jurgens, R. (2005). "Nothing about us without us". Greater, Meaningful Involvement of People Who Use Illegal Drugs: A Public Health, Ethical and Human Rights Approach. Toronto, ON: Canadian HIVIAIDS Legal Network. 
Kennedy, C. \& Fitzpatrick, S. 2001. Begging, rough sleeping and social exclusion: Implications for social policy. Urban Studies (Routledge), 38, 2001-2016.

Kingfisher, C. (2005). How the Housed View the Homeless: A Study of the 2002 Controversy in Lethbridge. Lethbridge, Alberta: University of Lethbridge.

Kingfisher, C. (2007). Discursive constructions of homelessness in a small city in the Canadian prairies. American Ethnologist, 34, 91-107.

Laurenson, P. \& Collins, D. (2006). Towards inclusion: Local government, public space and homelessness in New Zealand. New Zealand Geographer, 62, 185-195.

Lloyd, C. (2010). Sinning and sinned against: The stigmatization of problem drug users. London: UK Drug Policy Commission.

McDonald, C. (2012). Understanding participatory action research: A qualitative research methodology option. Canadian Jounal of Action Research, 13, 34-50.

Mikkonen, J. \& Raphael, D. (2010). Social determinants of health: The Canadian facts. Toronto, ON: York University.

Mirchandani, K. \& Chan, W. (2007). Criminalizing race, criminalizing poverty: Welfare fraud enforcement in Canada, Halifax, NS, Fernwood Publishing.

National Alliance to End Homelessness (2000) A Plan Not a Dream: How to End Homelessness in Ten Years. Washington, DC: National Alliance to End Homelessness.

Nelson, G., Stafancic, A., Rae, J., Townley, G., Tsemberis, S., Macnaughton, E., Hurtubise, R., Patterson, M., Stergiopoulous, V., Piat, M. \& Goering, P. (2014). Early implementation evaluation of a multi-site housing first intervention for homeless people with mental illness: A mixed methods approach. Evaluation and Program Planning, 43, 16-26.

Norman, T., \& Pauly, B. (2013). Including people who experience homelessness: A scoping review of the literature. International Journal of Sociology and Social Policy, 33(3/4), 136-151. doi:10.1108/01443331311308203.

O'Grady, B., Gaetz, S. \& Buccieri, K. (2011). Can I see your ID? The policing of youth homelessness in Toronto. Toronto: JFCY \& Homeless Hub.

Owen, R. (2009). Participation of people experiencing homelessness: Sharing the power and working together. The Magazine of FEANTSA: European Federation of National Organizations Working with the Homeless.

Paasche, S.( 2009). Promoting the participation of service users: The role of FEANTSA. The Magazine of FEANTSA: European Federation of National Organizations Working with the Homeless.

Pauly, B. (2014). Close to the street: Nursing care for people marginalized by homelessness and substance use. In M. Guirguis-Younger, S. Hwang \& R. McNeil (Eds.), Homelessness and health in Canada. Ottawa, ON: University of Ottawa Press.

Pauly, B. (2008). Harm reduction through a social justice lens. International Journal of Drug Policy, 19, 4-10. doi:10.1016/j.drugpo.2007.11.005.

Pauly, B., Jackson, N., Thompson, D., \& Kerr-Southin, M. (2011). Homeless and hungry in Victoria: Fitting the pieces together. Greater Victoria report on housing and supports 2011. Victoria, BC: Greater Victoria Coalition to End Homelessness.

Porter, D. \& Craig, D. (2004). The Third Way and the Third World: Poverty Reduction and Social Inclusion in the Rise of 'Inclusive' Liberalism. Review of International Political Economy, 11, 387-423.

Reitsma-Street, M. \& Wallace, B. (2004). Resisting two-year limits on welfare in British Columbia. Canadian Review of Social Policy, 169-176.

Reutter, L., Stewart, M., Veenstra, G., Love, R., Raphael, D. \& Makwarimba, E. (2009). "Who do they think we are anyway?" Perceptions of and responses to poverty stigma. Qualitative Health Research, 19, 297-312.

Room, R. (2005). Stigma, social inequality and alcohol and drug use. Drug and Alcohol Review, 24, 143-155. 
Ruff, C., Alexander, I. \& McKie, C. (2005). The use of focus group methodology in health disparities research. Nursing Outlook, 53, 134-140.

Sakamoto, I., Khandor, E., Chapra, A., Hendrickson, T., Maher, J., Roche, B. \& Chin, M. (2008). Homelessness- diverse experiences, common issues, shared solutions: The need for inclusion and accountability. Toronto, ON: Factor-Inwentash, Faculty of Social Work, University of Toronto.

Shapcott, M. (2009). Housing. In: RAPHAEL, D. (ed.) Social Determinants of Health. Toronto, ON: Canadian Scholar's Press Inc.

Sheehy, E. (2004). Advancing social inclusion: The implications for criminal law and policy. Canadian Journal of Criminology and Criminal Justice, 73-95.

Thorne, S., Kirkham, S. \& MacDonald-Eames, J. (1997). Interpretive description: A noncategorical qualitative alternative for developing nursing knowledge. Research in Nursing \& Health, 20, 169-177.

Thorne, S.(2008). Interpretive description, Walnut Creek, CA, Left Coast Press.

UNAIDS (1999). From Principle to Practice: Greater Involvement of People Living with or Affected by HIVIAIDS. Geneva: UNAIDS.

Van Draanen,, J., Harriot, D., Hwang, S., Jeyaratnam, J., Koo, M., O'Campo, P. \& Stergiopoulous, V. (2013). Meaningful inclusion of consumers in research and service delivery. Psychiatric Rehabilitation Journal, 36, 180-186.

Walsh, T. (2006). A right to inclusion? Homelessness, human rights and social exclusion. Australian Journal of Human Rights, 12, 185-204.

Whiteford, M. (2011). Square pegs, round holes: Rough sleeping and service user involvement? Practice, 23, 45-58.

Williams, J. (2005). The Politics of Homelessness: Shelter Now and Political Protest. Political Research Quarterly, 58, 497-509.

World Health Organization Europe. (2015). Social inclusion and health equity for vulnerable groups [Online]. Available: http://www.euro.who.int/en/health-topics/healthdeterminants/social-determinants/activities/social-inclusion-and-health-equity-forvulnerable-groups [Accessed November 15, 2015 2015]. 


\section{Biographical notes}

Trudy Norman returned to academia after twenty-five years working in community-based services to people who experience homelessness. She is an interdisciplinary (Nursing/Anthropology) doctoral candidate at the Centre for Addictions Research, University of Victoria, focusing specifically on homelessness. Her research interests currently center on the impact of unequal power relations on various aspects of social inclusion as well as activism and resistance by people with experience of homelessness.

Bernie Pauly is an Associate Professor in School of Nursing and Scientist at the Centre for Addictions Research of BC at the University of Victoria. She is a research collaborator with the Greater Victoria Coalition to End Homelessness. Her research focuses on health equity, homelessness, and substance use and the implementation of interventions that promote health equity in public health services and community responses to homelessness and substance use.

Hilary Marks has always been an advocate. Her passion for justice and rights permeates her volunteer work in the community. She was a peer interviewer with the Vancouver Island Public Interest Research Group from the University of Victoria on their Policing Poverty project. She is Co-Coordinator of the peer based Social Inclusion Advisory Group for the Greater Victoria Coalition to End Homelessness. She was the peer researcher on this project and hopes to contribute her skills and learning to future research efforts.

Dakota Palazzo has over 10 years experience providing comprehensive social and healthcare support to individuals facing mental health, addictions, homelessness, poverty and other overlapping barriers to wellness, both locally and globally. She is a Community Based Researcher, Licensed Practical Nurse, Residential Support Worker, advocate and volunteer. Her active interest and personal passion in improving the quality of life of individuals and building healthy communities are a motivating force in Dakota's everyday life. 